\title{
Effectiveness of a Regional Prepregnancy
Care Program in Women With Type 1 and Type 2 Diabetes
}

Benefits beyond glycemic control

Helen R. MuRPhy, MD ${ }^{1}$

JONATHAN M ROLAND, DM ${ }^{2}$

DAVID SIMMONS, MD ${ }^{4}$

ELEANOR GURNELL, MD ${ }^{5}$

NichOLAS J. MORRISH, MD ${ }^{6}$
Timothy C. SKINNER, PHD ${ }^{3}$

SHIU-CHING SoO, FRCP ${ }^{7}$

SuZANNAH Kelly, RM $^{8}$

BOON LIM, FRCOG ${ }^{9}$

JOANNE RANDALL, FRCP ${ }^{10}$

SARAH THOMPSETT, RGN ${ }^{11}$

Rosemary C. Temple, FrCP ${ }^{12}$

OBJECTIVE - To implement and evaluate a regional prepregnancy care program in women with type 1 and type 2 diabetes

RESEARCH DESIGN AND METHODS - Prepregnancy care was promoted among patients and health professionals and delivered across 10 regional maternity units. A prospective cohort study of 680 pregnancies in women with type 1 and type 2 diabetes was performed. Primary outcomes were adverse pregnancy outcome (congenital malformation, stillbirth, or neonatal death), congenital malformation, and indicators of pregnancy preparation (5 $\mathrm{mg}$ folic acid, gestational age, and AlC). Comparisons were made with a historical cohort $(n=613$ pregnancies) from the same units during 1999-2004.

RESULTS - A total of 181 (27\%) women attended, and 499 women (73\%) did not attend prepregnancy care. Women with prepregnancy care presented earlier ( 6.7 vs. 7.7 weeks; $P<0.001$ ), were more likely to take $5 \mathrm{mg}$ preconception folic acid $(88.2 \mathrm{vs.} 26.7 \% ; P<0.0001)$ and had lower AlC levels (AlC 6.9 vs. $7.6 \% ; P<0.0001$ ). They had fewer adverse pregnancy outcomes ( $1.3 \mathrm{vs.}$ $7.8 \% ; P=0.009)$. Multivariate logistic regression confirmed that in addition to glycemic control, lack of prepregnancy care was independently associated with adverse outcome (odds ratio 0.2 [95\% CI $0.05-0.89$ ]; $P=0.03$ ). Compared with 1999-2004, folic acid supplementation increased (40.7 vs. $32.5 \% ; P=0.006)$ and congenital malformations decreased ( 4.3 vs. $7.3 \% ; P=0.04$ ).

CONCLUSIONS - Regional prepregnancy care was associated with improved pregnancy preparation and reduced risk of adverse pregnancy outcome in type 1 and type 2 diabetes. Prepregnancy care had benefits beyond improved glycemic control and was a stronger predictor of pregnancy outcome than maternal obesity, ethnicity, or social disadvantage.

Diabetes Care 33:2514-2520, 2010

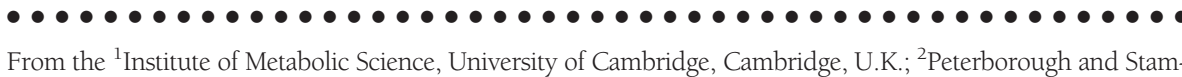
ford Hospitals, National Health Service (NHS) Foundation Trust, Healthy Living Centre, Peterborough, U.K.; ${ }^{3}$ Flinders University Rural Clinical School, Renmark, South Australia, Australia; ${ }^{4}$ the Institute of Metabolic Science, Cambridge University Hospitals, NHS Foundation Trust, Cambridge, U.K.; the ${ }^{5}$ Diabetes Department, West Suffolk Hospital, NHS Foundation Trust, Bury St. Edmunds, Suffolk, U.K.; the ${ }^{6}$ Diabetes Department, Bedford Hospital, NHS Foundation Trust, Bedford, U.K.; the ${ }^{7}$ Diabetes Department, Luton and Dunstable Hospital, NHS Foundation Trust, Luton, U.K.; the ${ }^{8}$ Department of Obstetrics and Gynecology, Ipswich Hospital, NHS Foundation Trust, Ipswich, U.K.; the ${ }^{9}$ Department of Obstetrics and Gynecology, Hinchingbrooke Health Care, NHS Foundation Trust, Huntingdon, U.K.; the ${ }^{10}$ Diabetes Department, James Paget Hospital, NHS FoundationTrust, Great Yarmouth, U.K.; the ${ }^{11}$ Diabetes Department, The Queen Elizabeth Hospital, Kings Lynn, U.K.; and the ${ }^{12}$ Elsie Bertram Diabetes Centre, Norfolk and Norwich University Hospital, NHS Foundation Trust, Norwich, U.K.

Corresponding author: Helen R. Murphy, hm386@medschl.cam.ac.uk.

Received 10 June 2010 and accepted 10 August 2010.

The views expressed in this publication are those of the authors and not necessarily those of the NHS, NIHR, or Department of Health.

DOI: $10.2337 / \mathrm{dc} 10-1113$

(C) 2010 by the American Diabetes Association. Readers may use this article as long as the work is properly cited, the use is educational and not for profit, and the work is not altered. See http://creativecommons. org/licenses/by-nc-nd/3.0/ for details.

The costs of publication of this article were defrayed in part by the payment of page charges. This article must therefore be hereby marked "advertisement" in accordance with 18 U.S.C. Section 1734 solely to indicate this fact.
}

See accompanying editorial, p. 2713.
$\mathbf{R}$ ates of adverse pregnancy outcome (congenital malformation, stillbirth, or neonatal death) in women with diabetes are three to five times greater than those of the background maternity population $(1,2)$. It is therefore recommended that all women of reproductive age with diabetes are offered annual preconception counseling and advised to avoid unplanned pregnancy (3). Prepregnancy care is the targeted support and additional clinical care offered to women planning pregnancy.

It is well established that for women with type 1 diabetes, specialist prepregnancy care improves glycemic control and reduces adverse pregnancy outcomes (4-11). Yet, despite documented benefits in selected centers of excellence, only two regional programs have been described, both almost 20 years ago $(4,11)$. Failure to improve prepregnancy care provision leaves a majority of women at increased risk of potentially preventable poor pregnancy outcomes. This was confirmed by the Confidential Enquiry for Maternal and Child Health, revealing that only $17 \%$ of U.K. maternity units offer prepregnancy care and that only $10 \%$ of women, mostly those with type 1 diabetes, attend (12).

Type 2 diabetes has now emerged as a growing concern in pregnancy (13). Women with type 2 diabetes are predominantly cared for in community settings and are unlikely to access specialist prepregnancy care. Studies (12,14-16) from the U.K., France, and Denmark demonstrate a clear association between poor pregnancy preparation and adverse pregnancy outcomes in type 2 diabetes. Women with type 2 diabetes also tend to be older, more obese, more ethnically diverse, more socially disadvantaged, and more likely to have concomitant comorbidities, factors that are all associated with poor pregnancy outcome (12).

The additional health inequalities, obesity, and obstetric risk factors of women with type 2 diabetes are not easily overcome by prepregnancy care. However, women with type 2 diabetes are more likely to take 
potentially harmful medications and to achieve stricter glycemic control. Hence, prepregnancy care may be even more effective for women with type 2 diabetes than women with type 1 diabetes.

The aim of this study was to evaluate the effectiveness of a regional prepregnancy care program on pregnancy preparation, glycemic control, and pregnancy outcomes in women with type 1 and type 2 diabetes.

\section{RESEARCH DESICN AND}

METHODS - We documented the potentially modifiable risk factors for adverse pregnancy outcomes in type 1 and type 2 diabetes (14) and established an interdisciplinary regional prepregnancy care team. We also performed a qualitative study to identify women's barriers to accessing prepregnancy care, namely beliefs that strict glycemic targets were unrealistic, poor relationships with health professionals, and desire for a lessmedicalized pregnancy (17).

\section{Prepregnancy care promotion}

A theoretically guided preconception leaflet (the East Anglican Study for Improving Pregnancy Outcomes in Women with Diabetes [EASIPOD] leaflet) with advice and telephone contacts for a prepregnancy care coordinator was mailed annually to all women aged 16-45 years identified from specialist and primary-care diabetes registers. We targeted health professionals including nurses, general practitioners, retinal-screening teams, health visitors, midwives, community pharmacists, and disseminated information via pharmacist medicine use reviews, structured education programs, local enhanced service agreements, and patient support groups.

\section{Prepregnancy and antenatal care delivery}

Prior to pregnancy, women with type 2 diabetes were predominantly cared for by primary-care teams in community settings and women with type 1 diabetes by specialist teams in hospital settings. Referrals were accepted from specialist providers, primary care, and directly from women who received the EASIPOD leaflet. Prepregnancy care was delivered in specialist clinics without additional funding using a standardized proforma (see the online appendix, available at http:// care.diabetesjournals.org/cgi/content/full/ dc10-1113/DC1). The content was standardized throughout the study period (10 January 2006 through 31 September
2009) but delivered by different health care providers (diabetes physician, specialist nurse, midwife, or obstetrician). Joint clinics with diabetes and obstetric input were held in three larger units $(\geq 30$ deliveries per year), whereas smaller units provided appointments with individual nurses or physicians. The same specialist multidisciplinary health care teams provided antenatal care to women with type 1 and type 2 diabetes during pregnancy.

\section{Data collection}

Pregnancies were registered as soon as contact with the antenatal team was established. A data collection proforma was completed for all registered pregnancies within 3 months of pregnancy completion. The project coordinator facilitated timely data collection, validation of data, and entry onto a study database.

\section{Maternal data}

Pregnancies were described as planned if contraception was discontinued for the purposes of pregnancy. All other pregnancies were unplanned. Preconception counseling was documentary evidence of a discussion regarding the pregnancy risks associated with diabetes. Prepregnancy care was defined as a woman working in partnership with health professionals to optimize pregnancy outcome and required documented attendance at a prepregnancy clinic.

Quintiles of deprivation were derived from the postcode of residence according to the East of England Index of Multiple Deprivations (IMD) scores. Maternal A1C levels were recorded up to 6 months preconception and at up to 4-8 weekly intervals during pregnancy. They were assayed using Diabetes Control and Complications Trial-aligned methodology (normal reference range 3.6-5.8\%) in accredited laboratories, with all centers participating in the national external qualityassurance program.

\section{Pregnancy outcome measures}

Miscarriage was defined as the spontaneous ending of pregnancy before 24 weeks. We recorded termination of pregnancy for fetal malformation and described all other terminations as nontherapeutic. Congenital malformations were confirmed by postmortem results, genetic findings, or correspondence and classified according to the European Surveillance of Congenital Anomalies system. Stillbirth was fetal death after 24 weeks and neonatal death as death of a live-born infant before 28 days. A serious adverse outcome was one that resulted in major congenital malformation (included termination), stillbirth, or neonatal death.

\section{Statistical analyses and power calculation}

Univariate analyses were performed using $\chi^{2}$ tests for categorical variables and $t$ tests for continuous variables. For multivariate analyses, logistic regression was used. The major hypothesis of interest was whether prepregnancy care was effective in reducing adverse pregnancy outcomes, independent of potential confounding variables. Therefore, the model included maternal age, type of diabetes, diabetes duration, A1C at booking, ethnicity, socioeconomic status, BMI, parity, and smoking history as predictors in addition to whether women received prepregnancy care.

The annual birth rate for the 10 centers in the study is $\sim 50,000$, of which 200 births are complicated by pregestational diabetes. We calculated that a sample size of 580 pregnancies would give $80 \%$ power to detect a $30 \%$ reduction in the rate of serious adverse outcomes assuming 50\% prepregnancy care uptake and $10 \%$ adverse outcomes.

RESULTS - During the 3-year study period, 686 pregnancies (median 77 per center [range 25-111]) were registered. Six pregnancies in women who moved into the region during pregnancy were excluded. For the remaining 680 pregnancies, there were no differences in the pregnancy-planning intentions ( 50\% planned) of women with type 1 and type 2 diabetes. Women with type 1 diabetes were more likely to have preconception counseling ( 54 vs. 32\%; $P<0.0001$ ). Overall, 181 (27\%) women attended prepregnancy care, with significantly more attendees having type 1 compared with type 2 diabetes (31 vs. 20\%; P < $0.0009)$. The median number of prepregnancy care visits was three (range, one to seven). Among 499 (73\%) women without prepregnancy care, 157 (32\%) had documented preconception counseling.

\section{Maternal characteristics}

Women who attended prepregnancy care were more likely to be white and less likely to live in a deprived area, smoke cigarettes, and to be overweight or obese (Table 1). However, almost half of the women who attended prepregnancy care 
did live in deprived areas (IMD quintiles 4-5).

\section{Pregnancy preparation}

Attendees were more likely to have had preconception counseling $(P<0.0001)$ and to have read the EASIPOD leaflet $(P<0.0001)$. They were more likely to have $5 \mathrm{mg}$ preconception folic acid (88 vs. $27 \%$; $P<0.0001$ ) and less likely to conceive on potentially harmful ACE inhibitors ( 1.1 vs. $4.6 \% ; P=0.05$ ) and/or statins ( 0 vs. $7.6 \% ; P=0.0003$ ). However, $10 \%$ of pregnancies occurred earlier than expected, some before folic acid (12\%) was started or ACE inhibitors were stopped (1\%).

Attendees presented earlier for antenatal care $(P<0.0001)$, with $70 \%$ having their first antenatal contact before 8 weeks. Their glycemic control was significantly better before pregnancy and at first contact $(P<0.0001)$, although only 53\% achieved $\mathrm{AlC} \leq 7 \%$, and even fewer (17.8\%) (10.9\% type 1 diabetes, 32\% type 2 diabetes) achieved the National Institute for Health and Clinical Excellence (NICE) glycemic control target AlC $<6.1 \%$.

\section{Pregnancy outcomes}

Detailed pregnancy outcomes are available for 676 pregnancies (665 singleton and 11 twin), excluding four pregnancies in women who moved out of the area ( $\mathrm{Ta}$ ble 2). There were 2 adverse outcomes (one malformation and one stillbirth) in women with prepregnancy care and 32 adverse outcomes (23 malformations, six stillbirths, and three neonatal deaths) in women without prepregnancy care (1.3 vs. $7.8 \% ; P=0.009)$. Gestational age at delivery and neonatal morbidity were comparable, with equal rates of preterm delivery (50 of 150 vs. 116 of $397 ; P=$ 0.4 ), large-for-gestational-age babies (70 of 145 vs. 170 of $372 ; P=0.7)$, and neonatal care admissions (50 of 147 vs. 152 of 386; $P=0.5$ ) in women who did and did not attend.

\section{Effects of prepregnancy care in type $\mathbf{2}$ compared with type 1 diabetes}

For women with type 1 diabetes, there were no differences in ethnicity or socioeconomic status of women with and without prepregnancy care (supplementary Table). As per the entire cohort, attendees had improved glycemic control and their offspring had reduced risk of adverse outcome (1.9 vs. $8.8 \% ; P=0.03$ ).

In women with type 2 diabetes, atten-
Table 1-Characteristics of pregnancies in women with type 1 and type 2 diabetes according to prepregnancy care attendance

\begin{tabular}{|c|c|c|c|}
\hline & PPC & No PPC & $P$ value \\
\hline Demographic data* & $n=181$ & $n=499$ & \\
\hline \multicolumn{4}{|l|}{ Age (years) } \\
\hline Median (10th-90th centile) & $33(26-39)$ & $31(22-39)$ & 0.002 \\
\hline \multicolumn{4}{|l|}{ Ethnicity } \\
\hline White & $166(91.7)$ & $387(77.6)$ & 0.0005 \\
\hline Asian & $12(6.6)$ & $90(18.0)$ & \\
\hline Other & $3(1.7)$ & $22(4.4)$ & \\
\hline Social deprivation & $n=177$ & $n=496$ & \\
\hline Quintile 1 (least deprived) & $30(16.9)$ & $65(13.1)$ & 0.01 \\
\hline Quintile 2 & $27(15.3)$ & $67(13.5)$ & \\
\hline Quintile 3 & $47(26.6)$ & $91(18.3)$ & \\
\hline Quintile 4 & $34(19.2)$ & $100(20.2)$ & \\
\hline Quintile 5 (most deprived) & $39(22.0)$ & $173(34.9)$ & \\
\hline Weight & $n=176$ & $n=451$ & \\
\hline \multicolumn{4}{|l|}{ Weight at booking (kg) } \\
\hline Median (10th-90th centile) & $71.5(56.9-99.0)$ & $74.5(58.0-105.0)$ & 0.03 \\
\hline \multicolumn{4}{|l|}{ BMI at booking $\left(\mathrm{kg} / \mathrm{m}^{2}\right)$} \\
\hline Median (10th-90th centile) & $26.1(21.3-36.2)$ & $27.9(22.2-38.1)$ & 0.005 \\
\hline Normal (BMI $\leq 24.9)$ & $73(41.5)$ & $131(29.0)$ & \\
\hline Overweight (BMI 25-29.9) & $45(25.6)$ & $147(32.6)$ & \\
\hline Obese (BMI $\geq 30)$ & $58(33.0)$ & $173(38.4)$ & \\
\hline Diabetes status & $n=181$ & $n=499$ & \\
\hline \multicolumn{4}{|l|}{ Diabetes duration (years) } \\
\hline Median (10th-90th centile) & $10(2-27)$ & $7(1-22)$ & 0.01 \\
\hline \multicolumn{4}{|l|}{ Maternal complications } \\
\hline Retinopathy & $43(23.8)$ & $91(18.2)$ & 0.1 \\
\hline Nephropathy & $5(2.8)$ & $11(2.2)$ & 0.9 \\
\hline Neuropathy & $3(1.7)$ & $10(2.0)$ & 1.0 \\
\hline \multicolumn{4}{|l|}{ Glycaemic control } \\
\hline \multicolumn{4}{|l|}{ AlC prepregnancy (\%) } \\
\hline Median (10th-90th centile) & $7.2(6.0-8.8)$ & $8.1(6.1-11.7)$ & $<0.0001$ \\
\hline \multicolumn{4}{|l|}{$\mathrm{AlC}$ at first contact (\%) } \\
\hline Median (10th-90th centile) & $6.9(5.8-8.8)$ & $7.6(6.0-10.1)$ & $<0.0001$ \\
\hline $\mathrm{AlC}<7.0 \% \dagger$ & $72 / 135(53.3)$ & $113 / 298(37.9)$ & 0.004 \\
\hline \multicolumn{4}{|l|}{ AlC first trimester (\%) } \\
\hline Median (10th-90th centile) & $6.9(5.8-8.4)$ & $7.4(6.0-9.7)$ & $<0.0001$ \\
\hline \multicolumn{4}{|l|}{ AlC second trimester (\%) } \\
\hline \multirow{2}{*}{\multicolumn{4}{|c|}{ AlC third trimester (\%) }} \\
\hline & & & \\
\hline Median (10th-90th centile) & $6.4(5.5-7.5)$ & $6.5(5.3-7.9)$ & 0.05 \\
\hline \multicolumn{4}{|l|}{ Diabetes treatment at conception } \\
\hline Diet alone & $4(2.2)$ & $69(13.8)$ & $<0.0001$ \\
\hline Insulin & $166(91.7)$ & $317(63.5)$ & $<0.0001$ \\
\hline Sulphonylurea & $0(0)$ & $16(3.2)$ & 0.03 \\
\hline Metformin & $40(22.1)$ & $124(24.8)$ & 0.5 \\
\hline Metformin alone & 12 & 107 & \\
\hline Metformin and insulin & 28 & 17 & \\
\hline Glitazone & $1(0.6)$ & $21(4.2)$ & 0.03 \\
\hline \multicolumn{4}{|l|}{ Diabetes therapy at delivery } \\
\hline Insulin & $154 / 154(100)$ & $384 / 408(94.1)$ & 0.004 \\
\hline \multicolumn{4}{|l|}{ Pregnancy preparation } \\
\hline Preconception counselling & 150/181 (82.9) & $157 / 496(31.7)$ & $<0.0001$ \\
\hline EASIPOD leaflet read & $68 / 156(43.6)$ & $67 / 451(14.9)$ & $<0.0001$ \\
\hline Planned pregnancy & $162 / 178(91)$ & $168 / 448(37.5)$ & $<0.0001$ \\
\hline Folic acid preconception & $157 / 178(88.2)$ & $112 / 420(26.7)$ & $<0.0001$ \\
\hline \multicolumn{4}{|l|}{ Potentially harmful medications } \\
\hline ACE inhibitor at conception & $2(1.1)$ & $23(4.6)$ & 0.05 \\
\hline Statin therapy at conception & $0(0)$ & $38(7.6)$ & 0.0003 \\
\hline Gestational age at booking (wee & & & \\
\hline Median (10th-90th centile) & $6.7(4.4-10.2)$ & $7.7(5.1-14.6)$ & $<0.0001$ \\
\hline & & & continued \\
\hline
\end{tabular}


Table 1-Continued

\begin{tabular}{lccr}
\hline & PPC & No PPC & P value \\
\hline Booked before 8/40 & $117 / 167(70.0)$ & $240 / 457(52.5)$ & 0.0001 \\
Smoking status at conception & $151(83.9)$ & $348(71.4)$ & 0.0002 \\
Nonsmoker & $15(8.3)$ & $34(7.0)$ & \\
Ex-smoker & $14(7.8)$ & $105(21.6)$ & \\
Current smoker &
\end{tabular}

Data are $n(\%)$ unless otherwise indicated. *Six pregnancies in women who moved into the area during pregnancy are excluded as details of their preconception counseling and prepregnancy care were lacking. $\uparrow$ The proportion of women achieving the more stringent NICE-recommended AlC target of $<6.1 \%$ introduced during this study was $17.8 \%$ women with prepregnancy care (10.9\% type 1 diabetes, $32 \%$ type 2 diabetes) vs. $10.4 \%$ (5.1\% type 1 diabetes, $16.5 \%$ type 2 diabetes) without prepregnancy care $(P=0.05)$.

Table 2-Pregnancy outcomes of women with diabetes according to prepregnancy care attendance

\begin{tabular}{|c|c|c|c|}
\hline & PPC & No PPC & $P$ value \\
\hline Pregnancy outcome $e^{1}$ & $n=181$ & $n=495$ & \\
\hline Miscarriage & $28(15.5)$ & $71(14.3)$ & 0.9 \\
\hline Termination of pregnancy & 1 & 25 & \\
\hline $\begin{array}{l}\text { Termination of pregnancy fetal } \\
\text { abnormality }\end{array}$ & 0 & 9 & 0.2 \\
\hline $\begin{array}{l}\text { Termination of pregnancy non- } \\
\text { diabetes associated* }\end{array}$ & 1 & 16 & \\
\hline Delivery $^{2}$ & $n=152$ & $n=399$ & \\
\hline $\begin{array}{l}\text { Gestational age at delivery (weeks) } \\
\text { Median (10th-90th centile) }\end{array}$ & $37.6(34.6-38.9)$ & $37.7(34.7-39.0)$ & 0.3 \\
\hline Type of delivery & & & \\
\hline SVD including instrumental & $53(34.9)$ & $177(44.4)$ & 0.05 \\
\hline LSCS & $99(65.1)$ & $222(55.6)$ & \\
\hline Planned LSCS & $49(32.2)$ & $101(25.3)$ & 0.6 \\
\hline Emergency LSCS & $50(32.9)$ & $121(30.3)$ & \\
\hline Twins & 5 & 6 & \\
\hline Perinatal morbidity & & & \\
\hline Prematurity $^{3}$ & $n=150$ & $n=397$ & \\
\hline$<37$ weeks gestation & $50(33.3)$ & $116(29.2)$ & 0.4 \\
\hline$<34$ weeks gestation & $9(6.0)$ & $27(6.8)$ & 0.9 \\
\hline Infant birth weight centiles ${ }^{4}$ & $n=145$ & $n=372$ & \\
\hline Large for gestational age & $70(48.3)$ & $170(45.7)$ & 0.7 \\
\hline Extremely large for gestational age & $50(34.4)$ & $114(30.6)$ & 0.5 \\
\hline Small for gestational age & $7(4.8)$ & $32(8.6)$ & 0.2 \\
\hline Neonatal care ${ }^{5}$ & $n=147$ & $n=386$ & 0.5 \\
\hline Home birth & $0(0)$ & $1(0.3)$ & \\
\hline Postnatal ward & $74(48.3)$ & $183(47.4)$ & \\
\hline Level 1 & $23(15.6)$ & $50(13.0)$ & \\
\hline Level 2 & $37(25.2)$ & $123(31.9)$ & \\
\hline Level 3 & $13(8.8)$ & $29(7.5)$ & \\
\hline Pregnancy outcomes ${ }^{6}$ & $n=152$ & $n=408$ & \\
\hline Malformation & $1(0.7)$ & $23(5.6)$ & 0.02 \\
\hline Stillbirth & $1(0.7)$ & $6(1.5)$ & 0.7 \\
\hline Neonatal death & $0(0)$ & $3(0.7)$ & 0.7 \\
\hline Perinatal mortality & $1(0.7)$ & $9(2.2)$ & 0.4 \\
\hline
\end{tabular}

Serious adverse outcome (malformation

with or without termination of

preganancy, stillbirth, or neonatal death)

$2(1.3)$

$32(7.8)$

0.009

Data are $n(\%)$ unless otherwise indicated. ${ }^{1}$ All pregnancies excluding four pregnancies in women who moved out of the area during pregnancy $(n=676) .{ }^{*}$ We are confident that all pregnancy termination data in women with prepregnancy care are included but cannot exclude an even higher number of nontherapeutic terminations in women without prepregnancy care. ${ }^{2}$ All pregnancies after 20 weeks' gestation excluding 99 spontaneous miscarriages and 26 terminations $(n=551)$. ${ }^{3}$ All pregnancies excluding four infants for whom data on gestational age at delivery were missing $(n=547) .{ }^{4}$ All pregnancies resulting in live singleton births excluding 18 for whom birth weight centiles were missing $(n=517) .{ }^{5}$ All pregnancies resulting in live singleton births excluding one infant in whom care level was not recorded $(n=533) .{ }^{6}$ All pregnancies after 20 weeks' gestation (551) and 9 terminations for congenital malformation $(n=560)$. dance was poor (20\%). However, despite their better glycemic control (compared with women with type 1 diabetes), prepregnancy care attendees still achieved significantly better glycemic control both before pregnancy $(P<$ 0.0001 ) and throughout the first two trimesters $(P=0.007$ and $P=0.03)$. There were no malformations or adverse outcomes in the offspring of attendees compared with 10 malformations (5.6\%) and 12 adverse outcomes (6.8\%) in the offspring of women without prepregnancy care, but with small numbers these differences were not significant.

\section{Predictors of serious adverse pregnancy outcome}

In contrast to the general maternity population, maternal age, parity, obesity, ethnicity, and socioeconomic deprivation were not independently associated with adverse outcome (Table 3). The independent predictors were glycemic control at booking (odds ratio 1.46 [95\% CI 1.161.85]; $P=0.001$ per $1 \%$ AlC increase) and lack of prepregnancy care (0.2 [0.050.89 ]; $P=0.03$ ). Diabetes duration and type 1 diabetes approached, but did not reach, significance $(P=0.06$ and $P=0.07)$.

\section{Pregnancy outcomes during 2006- 2009 compared with during 1999-2004}

Notable differences were the increased proportion of pregnancies complicated by type 2 diabetes ( 40 vs. $27 \%$; P < 0.0001 ), increased preconception counseling and folic acid supplementation particularly in type 1 diabetes, and increased metformin use in type 2 diabetes (Table 4). Despite fewer malformations (4.3 vs. $7.3 \% ; P=0.04)$ during the prepregnancy care program, overall differences in perinatal mortality ( 1.8 vs. $3.7 \% ; P=0.07$ ) and adverse outcome (6.0 vs. $9.2 \%$; $P=$ 0.07 ) were not significant. Rates of adverse outcomes were unchanged (6.5\%) in type 1 diabetes. In type 2 diabetes, there were reductions both in adverse outcomes (5.3 vs. $16.4 \% ; P=0.0008$ ) and in malformations ( 4.5 vs. $12.3 \% ; P=0.009$ ).

CONCLUSIONS - Here, we report the development and evaluation of a regional prepregnancy care program, implemented in routine care, which was associated with improved glycemic control and reduced risk of adverse pregnancy outcome in pregnancies complicated by both type 1 and type 2 diabetes. Approximately half the women 
Table 3-Independent predictors of serious adverse pregnancy outcome (major congenital malformation, stillbirth, or neonatal death) in pregnancies complicated by type 1 and type 2 diabetes
Variable

Age (years) ${ }^{1}$

Type 1 diabetes $^{2}$

Duration of diabetes (years) ${ }^{3}$

AlC at booking ${ }^{4}$

European ethnicity

Social disadvantage

Prepregnancy care ${ }^{5}$

BMI

Parity $^{6}$

Smoking

Odds ratio (95\% CI)

$1.01(0.93-1.09)$
$3.41(0.89-13.0)$
$1.06(1.00-1.12)$
$1.46(1.16-1.85)$
$0.36(0.09-1.46)$
$1.00(0.76-1.32)$
$0.20(0.05-0.89)$
$0.95(0.88-1.03)$
$1.77(0.75-4.14)$
$1.41(0.93-2.15)$

$P$ value

0.9

0.07

0.06

0.001

0.2

1.0

0.03

0.2

0.2

0.1
${ }^{1}$ Increase in risk for every extra year of age. ${ }^{2}$ Increase in risk for women with type 1 diabetes as opposed to type 2 diabetes. ${ }^{3}$ Increase in risk for every extra year of diabetes duration. ${ }^{4}$ Increase in risk for every extra $1 \%$ of AlC. ${ }^{5}$ Decrease in risk for women who attend a prepregnancy care clinic as compared with women who did not attend prepregnancy care. ${ }^{6}$ Increase in risk for multiparous women as opposed to primiparous women.

had planned pregnancies and documented preconception counseling, suggesting fairly widespread health care interaction. However, less than a third benefited from prepregnancy care, suggesting failings of conventional models of engagement. This emphasizes the need to rethink how preconception counseling is delivered both at a population level and to women with preexisting medical conditions. In the U.K., preconception services are fragmented and variable, comparing poorly to other European countries, where effective prepregnancy care has been successfully implemented (2).

In contrast to other U.K. and U.S. studies, we found no association between social disadvantage and prepregnancy care attendance in women with type 1 diabetes $(18,19)$. Ethnicity and living in a deprived area were barriers to access only in women with type 2 diabetes. Our qualitative study suggested that unrealistic glycemic control targets, poor communication, and "too much emphasis on all the bad things that could happen" are important barriers to engagement both for women with type 1 and type 2 diabetes (17), further emphasizing the need to deliver prepregnancy care in a positive, motivating, and supportive manner.

In this cohort, neither age, parity, ethnicity, social disadvantage, nor obesity predicted adverse pregnancy outcome. This could be because the study was underpowered to examine these effects or because glycemic control and pregnancy preparation are the strongest influences of adverse outcome in pregnancies complicated by type 1 and type 2 diabetes.

\section{Challenges in type 1 diabetes}

Even motivated attendees struggled to achieve optimal preconception glycemic control. Among women with type 1 diabetes, only $10 \%$ with prepregnancy care and 5\% without prepregnancy care achieved AlC levels <6.1\% compared

Table 4-Indicators of pregnancy preparation and pregnancy outcomes during the 2006-2009 regional prepregnancy care program compared with during 1999-2004

\begin{tabular}{|c|c|c|c|c|}
\hline & 1999-2004 & 2006-2009 & & $P$ value \\
\hline \multicolumn{5}{|l|}{ Type of diabetes ${ }^{1}$} \\
\hline Type 1 & 443 & 408 & & \multirow[t]{2}{*}{$<0.0001$} \\
\hline Type 2 & $162(26.8)$ & $274(40.2)$ & & \\
\hline Pregnancy loss $<20 / 40$ & $60 / 613(9.8)$ & $125 / 686(18.5)$ & & \multirow{4}{*}{$\begin{array}{c}<0.0001 \\
0.04\end{array}$} \\
\hline Preconception counselling ${ }^{2}$ & $200 / 535(32.5)$ & $245 / 562(43.6)$ & & \\
\hline Type 1 diabetes & $153 / 389(40.5)$ & $178 / 337(52.8)$ & & \\
\hline Type 2 diabetes & $42 / 146(28.7)$ & $67 / 225(29.8)$ & & \\
\hline Folic acid preconception & $174 / 535(32.5)$ & $229 / 562(40.7)$ & & \multirow[t]{3}{*}{0.006} \\
\hline Type 1 diabetes & $142 / 389(36.4)$ & $155 / 337(46.0)$ & & \\
\hline Type 2 diabetes & $32 / 146(21.9)$ & $74 / 225(32.9)$ & & \\
\hline \multicolumn{5}{|l|}{ Metformin } \\
\hline Type 2 diabetes & $51 / 146(35.2)$ & $123 / 225(54.7)$ & & 0.0003 \\
\hline \multicolumn{5}{|l|}{ Pregnancy outcome ${ }^{2}$} \\
\hline Congenital malformation & $39 / 535(7.3)$ & $24 / 562(4.3)$ & & \multirow{3}{*}{$\begin{array}{l}0.04 \\
(P=0.05 \text { for interaction })\end{array}$} \\
\hline Type 1 & $17 / 389(4.4)$ & $14 / 337(4.2)$ & 1.0 & \\
\hline Type 2 & $18 / 146(12.3)$ & $10 / 225(4.4)$ & 0.009 & \\
\hline Perinatal mortality & $20 / 535(3.7)$ & $10 / 562(1.8)$ & & \multirow{3}{*}{$\begin{array}{l}0.07 \\
(P=0.03 \text { for interaction })\end{array}$} \\
\hline Type 1 & $11 / 389(2.8)$ & $8 / 337(2.4)$ & 0.9 & \\
\hline Type 2 & $9 / 146(6.2)$ & $2 / 225(0.9)$ & 0.009 & \\
\hline Serious adverse outcome & $49 / 535(9.2)$ & $34 / 562(6.0)$ & & \multirow{3}{*}{$\begin{array}{l}0.07 \\
(P=0.007 \text { interaction })\end{array}$} \\
\hline Type 1 & 25/389 (6.4) & $22 / 337(6.5)$ & 0.9 & \\
\hline Type 2 & $24 / 146(16.4)$ & $12 / 225(5.3)$ & 0.0008 & \\
\hline
\end{tabular}

Data in parentheses are percentages. ${ }^{1}$ Includes all registered pregnancies in women with type 1 and type 2 diabetes during the 2 study periods. ${ }^{2}$ For direct comparison with the 1999-2004 study, we have excluded all pregnancies that resulted in miscarriage at $<20$ weeks' gestation and all terminations for indications other than congenital malformation. 
with 32 and $16.5 \%$, respectively, of women with type 2 diabetes. It should be noted that only a minority of women (9.4\%) used insulin pump therapy before or during pregnancy and that continuous glucose monitoring was not routinely available. Consequently, despite improved pregnancy preparation in women with type 1 diabetes, their glycemic control and risk of adverse pregnancy outcome were disappointingly unchanged over the two study periods. A nationwide Swedish study of over 5,000 pregnancies also concluded that type 1 diabetes is still associated with considerably increased adverse obstetric and perinatal outcomes, again highlighting a lack of progress over the past decade (20).

There is emerging evidence supporting the benefits of continuous glucose monitoring both before and during pregnancy $(21,22)$. Large multicenter studies are now needed to evaluate the effects and cost effectiveness of continuous glucose monitoring on maternal glycemic control and pregnancy outcomes. Recent innovations, including sensor-augmented insulin pumps and closed-loop technologies, may also help more women with type 1 diabetes to achieve near normoglycaemia $(23,24)$.

\section{Improvements in type 2 diabetes}

This study has highlighted encouraging improvements for pregnant women with type 2 diabetes, with significant reductions in rates of adverse pregnancy outcomes, over the past decade. This may represent a milder glycemic disturbance (25) and/or improvements in the management of type 2 diabetes. Importantly, it suggests that organized efforts to improve preconception glycemic control can have a beneficial effect for women with type 2 diabetes despite their obstetric risk factors.

\section{Strengths and limitations}

We carefully documented the maternal demographics and obstetric and diabetes risk factors in a large, contemporary cohort of women with diabetes. The program was implemented across 10 regional maternity units, reducing selection bias from specialist centers of excellence. A major strength is the inclusion of women with both type 1 and type 2 diabetes and the detailed content and delivery format for prepregnancy care, which previous studies lack. Furthermore, we evaluated the role of prepregnancy care in addition to preconception counseling and in- cluded details of preconception medication use and of pregnancy terminations, documenting the prevalence of terminations (both therapeutic and nontherapeutic) in women with diabetes.

A limitation is that it is not a randomized trial, and differences in the motivation of women who do and do not attend prepregnancy care are likely. However, a randomized trial is neither ethical nor clinically feasible. We therefore performed a robust observational cohort study, documenting and correcting for potential confounding factors, including age, parity, obesity, ethnicity, and socioeconomic status. We also have a historical cohort with details of pregnancy outcomes in the same centers before and during the program (14).

Prepregnancy care has failed to keep pace with recent educational and technological developments. Structured programs with evidence-based curriculums, standardized delivery by trained health professionals, and access to continuous glucose monitoring and insulin pump therapy are urgently required. For women with diabetes, prepregnancy care is as essential as antenatal care and needs to be resourced, quality assured, and researched to a similar standard. More work is needed to increase attendance, overcome the socioeconomic and ethnic barriers to access in type 2 diabetes, and to further improve glycemic control in type 1 diabetes.

Acknowledgments - This work was supported by Diabetes UK Project Grant BDA 06/ 0003197. H.R.M. is funded by a National Institute for Health Research (NIHR) Research Fellowship (PDF/08/01/036).

No potential conflicts of interest relevant to this article were reported.

H.R.M., J.M.R., and R.C.T. designed the study, interpreted the data, and wrote the manuscript. J.M.R., D.S., S.T., E.G., N.J.M., S.C.S., S.K., and B.L. provided clinical care and supervised data collection. All authors reviewed/edited the manuscript. T.C.S. developed the EASIPOD preconception leaflet available at http://www.diabetes.org.uk/ professionals/shared_practice/care_topics/ pregnancy/easipod_East_Anglian_Study_for_ Improving_Pregnancy_outcomes_in_women_ with_diabetes/.

Parts of this manuscript were presented in abstract form at the Diabetes UK Annual Professional Conference, 4 March 2010 and the European Association for the Study of Diabetes (EASD) Diabetes Pregnancy Study Group, 26 September 2009.

We thank the regional diabetes clinicians, obstetricians, nurses, and midwives for accurate data collection and excellent clinical care; Sian Evans (Eastern Region Public Health Observatory) for maternal deprivation scores; and Peter Campbell (Sanger Institute, Cambridge, U.K.) for statistical input.

\section{References}

1. Macintosh MC, Fleming KM, Bailey JA, Doyle P, Modder J, Acolet D, Golightly S, Miller A. Perinatal mortality and congenital anomalies in babies of women with type 1 or type 2 diabetes in England, Wales, and Northern Ireland: population based study BMJ 2006;333:177

2. Evers IM, de Valk HW, Visser GH. Risk of complications of pregnancy in women with type 1 diabetes: nationwide prospective study in the Netherlands. BMJ 2004; 328:915

3. NICE guideline 63: Diabetes in Pregnancy. Managment of diabetes and its complications in pregnancy from the preconception to the postnatal period. wwwniceorg 2008

4. Willhoite MB, Bennert HW Jr, Palomaki GE, Zaremba MM, Herman WH, Williams JR, Spear NH. The impact of preconception counseling on pregnancy outcomes. The experience of the Maine Diabetes in Pregnancy Program Diabetes Care 1993;16:450-455

5. Damm P, Molsted-Pedersen L. Significant decrease in congenital malformations in newborn infants of an unselected population of diabetic women. Am J Obstet Gynecol 1989;161:1163-1167

6. Steel JM, Johnstone FD, Hepburn DA, Smith AF. Can prepregnancy care of diabetic women reduce the risk of abnormal babies? BMJ 1990;301:1070-1074

7. Kitzmiller JL, Gavin LA, Gin GD, Jovanovic-Peterson L, Main EK, Zigrang WD. Preconception care of diabetes. Glycemic control prevents congenital anomalies JAMA 1991;265:731-736

8. Rosenn B, Miodovnik M, Combs CA, Khoury J, Siddiqi TA. Pre-conception management of insulin-dependent diabetes: improvement of pregnancy outcome. Obstet Gynecol 1991;77:846-849

9. Pregnancy outcomes in the Diabetes Control and Complications Trial. Am J Obstet Gynecol 1996;174:1343-1353

10. Temple RC, Aldridge VJ, Murphy HR. Prepregnancy care and pregnancy outcomes in women with type 1 diabetes. Diabetes Care 2006;29:1744-1749

11. Cousins L, Kitzmiller J, Schneider J, Pierce J, McCoy D, DeVore S, Yonekura L, Zlotnick C, Henry J, Darany J The California Diabetes and Pregnancy Program: implementation of a multicenter experience with diabetic pregnancies. J Perinatol 1992;12:173-180

12. Confidential Enquiry into Maternal and Child Health. Pregnancy in Women with 
type 1 and type 2 diabetes in 2002-03, England, Wales and Northern Ireland. CEMACH: London 2005

13. Feig DS, Palda VA. Type 2 diabetes in pregnancy: a growing concern. Lancet 2002;359:1690-1692

14. Roland JM, Murphy HR, Ball V, Northcote-Wright J, Temple RC. The pregnancies of women with Type 2 diabetes: poor outcomes but opportunities for improvement. Diabet Med 2005;22: 1774-1777

15. Boulot P, Chabbert-Buffet N, d'Ercole C, Floriot M, Fontaine P, Fournier A, Gillet JY, Gin H, Grandperret-Vauthier S, Geudj AM, Guionnet B, Hauguel-de-Mouzon S, Hieronimus S, Hoffet M, Jullien D, Lamotte MF, Lejeune V, Lepercq J, Lorenzi F, Mares P, Miton A, Penfornis A, Pfister B, Renard E, Rodier M, Roth P, Sery GA, Timsit J, Valat AS, Vambergue A, VerierMine $\mathrm{O}$. French multicentric survey of outcome of pregnancy in women with pregestational diabetes. Diabetes Care 2003;26:2990-2993

16. Clausen TD, Mathiesen E, Ekbom P, Hellmuth E, Mandrup-Poulsen T, Damm P. Poor pregnancy outcome in women with type 2 diabetes. Diabetes Care 2005;28:
323-328

17. Murphy HR, Temple RC, Ball VE, Roland JM, Steel S, Zill EHR, Simmons D, Royce LR, Skinner TC. Personal experiences of women with diabetes who do not attend pre-pregnancy care. Diabet Med 2010;27: 92-100

18. Holing EV, Beyer CS, Brown ZA, Connell FA. Why don't women with diabetes plan their pregnancies? Diabetes Care 1998; 21:889-895

19. Tripathi A, Rankin J, Aarvold J, Chandler C, Bell R. Preconception counseling in women with diabetes: a population-based study in the north of England. Diabetes Care 2009; 33:586-588

20. Persson M, Norman M, Hanson U. Obstetric and perinatal outcomes in type 1 diabetic pregnancies: A large, populationbased study. Diabetes Care 2009;32: 2005-2009

21. Tamborlane WV, Beck RW, Bode BW, Buckingham B, Chase HP, Clemons R, Fiallo-Scharer R, Fox LA, Gilliam LK, Hirsch IB, Huang ES, Kollman C, Kowalski AJ, Laffel L, Lawrence JM, Lee J, Mauras N, O'Grady M, Ruedy KJ, Tansey M, Tsalikian E, Weinzimer S, Wilson DM, Wolpert H, Wysocki T, Xing D. Continuous glucose monitoring and intensive treatment of type 1 diabetes. NEngl J Med 2008;359:1464-1476

22. Murphy HR, Rayman G, Lewis K, Kelly S, Johal B, Duffield K, Fowler D, Campbell PJ, Temple RC. Effectiveness of continuous glucose monitoring in pregnant women with diabetes: randomised clinical trial. BMJ 2008;337:a1680

23. Bergenstal RM, Tamborlane WV, Ahmann A, Buse JB, Dailey G, Davis SN, Joyce C, Peoples T, Perkins BA, Welsh JB, Willi SM, Wood MA Effectiveness of Sensor-Augmented Insulin-Pump Therapy in Type 1 Diabetes. N Engl J Med 2010

24. Hovorka R, Allen JM, Elleri D, Chassin LJ, Harris J, Xing D, Kollman C, Hovorka T, Larsen AM, Nodale M, De Palma A, Wilinska ME, Acerini CL, Dunger DB Manual closed-loop insulin delivery in children and adolescents with type 1 diabetes: a phase 2 randomised crossover trial. Lancet 2010

25. Balsells M, Garcia-Patterson A, Gich I, Corcoy R. Maternal and fetal outcome in women with type 2 versus type 1 diabetes mellitus: a systematic review and metaanalysis. J Clin Endocrinol Metab 2009; 94:4284-4291 


\section{University Library}

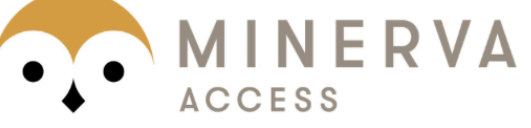

A gateway to Melbourne's research publications

Minerva Access is the Institutional Repository of The University of Melbourne

Author/s:

Murphy, HR;Roland, JM;Skinner, TC;Simmons, D;Gurnell, E;Morrish, NJ;Soo, S-C;Kelly,

S;Lim, B;Randall, J;Thompsett, S;Temple, RC

Title:

Effectiveness of a Regional Prepregnancy Care Program in Women With Type 1 and Type 2 Diabetes Benefits beyond glycemic control

Date:

2010-12-01

Citation:

Murphy, H. R., Roland, J. M., Skinner, T. C., Simmons, D., Gurnell, E., Morrish, N. J., Soo, S. -C., Kelly, S., Lim, B., Randall, J., Thompsett, S. \& Temple, R. C. (2010). Effectiveness of a Regional Prepregnancy Care Program in Women With Type 1 and Type 2 Diabetes Benefits beyond glycemic control. DIABETES CARE, 33 (12), pp.2514-2520. https://doi.org/10.2337/ dc10-1113.

Persistent Link:

http://hdl.handle.net/11343/263130

License:

CC BY-NC-ND 